\title{
Persistent wheezing in infants with an atopic tendency responds to inhaled fluticasone
}

\author{
R J Chavasse, Y Bastian-Lee, H Richter, T Hilliard, P Seddon
}

\begin{abstract}
Background-The role of inhaled corticosteroids for the treatment of wheeze in infancy remains unclear.

Aim-To investigate the effect of inhaled fluticasone on symptoms in a group of wheezy infants who had a high risk of progressing to childhood asthma.

Methods-A total of 52 infants, under 1 year of age, with a history of wheeze or cough and a history (personal or first degree relative) of atopy were prescribed either $150 \mu \mathrm{g}$ fluticasone twice daily (group F) or placebo (group P), via metered dose inhaler, for 12 weeks following a two week run in period. Symptoms were scored in a parent held diary and the mean daily symptom score (MDS) and symptom free days (SFD) calculated for each two week period.

Results-Thirty seven infants completed the study. Both MDS and SFD improved significantly between the run in and final two week period in group $F$, but not group $P$, with a mean difference in change $(95 \%$ CI) between groups of $1.12(0.05$ to 2.18$)$ for MDS and median difference of 3.0 (0.002 to 8.0) for SFD.

Conclusion-Improvement of clinical symptoms in response to fluticasone can be shown in this high risk group of infants. In the absence of effective alternatives inhaled corticosteroids should be considered in this patient group.

(Arch Dis Child 2001;85:143-148)
\end{abstract}

Keywords: fluticasone; asthma; wheeze; corticosteroid; inhaled

Wheeze in infancy is a common symptom and sign. It may be associated with breathing difficulty and cough and may often lead to the parent seeking consultation with the medical profession. Acute wheeze is also a frequent cause for referral and admission to hospital. Wheeze can be a presenting feature of many conditions (for example, cystic fibrosis, bronchomalacia) but far more commonly is a manifestation of the conditions variously labelled as wheezy bronchitis, infantile asthma, viral induced wheeze, and bronchiolitis. ${ }^{1}$ As such, the prognosis of wheeze in this age group is variable, depending on the cause and the presence of an underlying condition.

The treatment for wheeze in infancy has also caused controversy for some time. The intricacy of delivering topical medication and the trouble associated with measuring a response in this age group have contributed to this uncertainty.
Necessity for treatment is further clouded by the good prognosis of the majority of the patients. More than $60 \%$ of patients who wheeze during the first three years of life will not continue to be symptomatic at 6 years of age. ${ }^{2}$ However, a proportion of infants who wheeze within the first year of life continue with symptoms, becoming recognised as asthma, throughout childhood. Early effective treatment may not just relieve symptoms at the time, but may potentially alter long term prognosis. ${ }^{3}$

Many studies have shown that inhaled bronchodilators such as salbutamol have little or no effect in the relieving of wheeze in this age group. ${ }^{4-6}$ Suggested reasons for this lack of efficacy have included the dose delivered or the lack of response from the $\beta$ receptors in the lung. It is, perhaps, more likely that the relative importance of mechanisms producing wheeze are different in infants compared to older patients with asthma and that the reduction in airway calibre is less as a result of bronchial hyperreactivity and smooth muscle constriction than to airway tone and oedema secondary to inflammation.

Inhaled corticosteroids are the cornerstone of preventive therapy for asthma in older children and adults because of their role in reducing airway inflammation. The place of inhaled corticosteroids in the treatment of infants who wheeze remains unclear. Theoretical benefit of anti-inflammatory action is counterbalanced by concerns about lung and somatic growth. ${ }^{8}$

Specific therapeutic trials have not helped define their role in infants. A mixed clinical response has been shown, ${ }^{9-11}$ with no obvious improvement in pulmonary function, ${ }^{11}$ although studies recruiting slightly older patients have proved more hopeful. ${ }^{12-15}$ Evidence for the use of steroids in symptoms associated with viral bronchiolitis in either the acute ${ }^{1617}$ or chronic ${ }^{18-20}$ phase is almost uniformly negative.

We aimed to measure the response to inhaled fluticasone propionate (Glaxo Wellcome, Middlesex, UK) in a group of infants with significant wheeze who were selected as having a high risk of progressing to childhood asthma. Although atopy is less important as a trigger in the first two years of life, an atopic tendency is associated with a higher risk of wheeze persisting throughout childhood. Fluticasone was chosen as the inhaled corticosteroid because its high first pass metabolism may potentially minimise systemic side effects.

\section{Methods}

Infants were recruited from hospital outpatient clinics and by referral from general practitioners following a mail shot. A small number of 
patients were identified following an admission to the ward with a wheezing illness. Inclusion criteria were:

(1) Age between 3 and 12 months

(2) Documented history of: persistent wheeze (occurring on at least three days per week for six weeks); or persistent cough (occurring on at least three nights per week for six weeks); or recurrent wheeze (occurring on at least three occasions over the previous three months)

(3) Personal history of eczema or family history of atopy (eczema, asthma, or seasonal rhinitis) in a first degree relative.

The infants were examined at recruitment by the research team (RC, TH, YBL, HR) and symptoms documented. Wheeze was not always evident at the first consultation.

Infants were not considered for inclusion if they had a history of preterm birth before 34 weeks, had required a period of mechanical ventilation, or had a major congenital malformation. Infants who were already regularly using inhaled corticosteroids were also excluded. Infants who had received a short course of oral steroid were not excluded, but recruitment was deferred until one month after the treatment course if they still fulfilled the recruitment criteria. All infants had initially participated in a trial of inhaled salbutamol reported previously. ${ }^{6}$

The study was double blind, randomised, and placebo controlled using a parallel group design. Following a two week run in period, subjects were randomised to receive either inhaled fluticasone propionate $150 \mu \mathrm{g}$ (three activations, $50 \mu \mathrm{g}$ per activation) twice daily or placebo (three activations) twice daily, for a period of 12 weeks. Both inhalers looked identical, were unmarked, and were dispensed from the hospital pharmacy using a coded prescription. The inhalers were administered through a Babyhaler (small volume spacer and mask, Glaxo Wellcome). The parents were both taught and given written instructions on optimal use of the Babyhaler. Throughout the whole study period, each infant had an active salbutamol inhaler that could be administered for relief (200-400 $\mu \mathrm{g}$, four hourly) if required, in conjunction with the study inhaler.

The study was explained to the parent(s) and they were given a written information sheet. Written consent to participate was obtained. The study had full approval from the Brighton Area Ethics Committee.

At the first visit, each subject had a history taken and was examined fully. Weight (Seca 834, Birmingham, UK) and height (Kiddimetre, Raven Equipment Ltd, Castlemead Publications, Ware, UK) were recorded.

The parent(s) were asked to record symptoms of wheeze and cough, twice each day (morning and evening) in a diary (modified from Noble and colleagues ${ }^{9}$ and Richter and Seddon $^{18}$ ). Each symptom was scored between 0 and 3 for the preceding period corresponding to night and daytime. This gave a total daily symptom score with a maximum of 12 points equating to maximum symptoms. The number of doses of salbutamol administered each day was also recorded in the diary.

The infants were re-examined midway through the study (after completing the run in period and six weeks of randomised treatment) at which time inhaler technique was checked, diaries changed, and replacement inhalers dispensed. At the end of the study, each infant was re-examined with weight and length recorded, and the second diary collected. An independent clinician then counselled the parents and recommended ongoing treatment.

At the completion of the whole study, the data from the diaries were analysed (RC, YBL) prior to knowledge of the treatment group. All the components of each day's score were entered onto a spreadsheet. From these the mean daily symptom score (MDS) was calculated for each two week period (run in and treatment periods 1-6). The main comparison was between the run in and the final two weeks (period 6) of the study. The scores for each component symptom were also assessed.

The number of days within each period on which the daily score equalled zero were counted as symptom free days (SFD). As a marker of severe symptoms or exacerbation, days with a score greater than six were totalled for each period. These were arbitrarily called the exacerbation days (ED).

Infants had baseline pulmonary function tests performed at a suitable time during the run in period as described previously. ${ }^{6}$ Following sedation with triclofos, resistance of the respiratory system $\left(R_{\mathrm{rs}}\right)$ was measured by the single breath occlusion technique with the average $R_{r s}$ calculated from five technically acceptable occlusions. Maximal flow at functional residual capacity $\left(\mathrm{V}_{\operatorname{maxFRC}}^{\prime}\right)$ was measured by the rapid thoracoabdominal compression technique. The mean $\mathrm{V}_{\text {maxFRC }}$ was calculated from three technically acceptable manoeuvres.

A single blood sample for IgE enzyme immunoassay (Cobas Core Analyser, Roche, UK; performed by $\mathrm{Mr}$ A Wise, Protein Reference Unit, St George's Hospital, London, UK) was also taken at a suitable time during the run in period.

RANDOMISATION

Sealed randomisation envelopes were generated by Glaxo Wellcome using a validated random number generation programme, PACT. ${ }^{21}$ Randomisation occurred in blocks of four.

\section{STATISTICS}

Comparison in MDS, SFD, and ED between the start and the end of the study within each treatment group was made by paired $t$ test, and between groups by two sample $t$ testing. Where data were not normally distributed, analysis was by Mann-Whitney test. Categorical data were analysed using $\chi^{2}$ or Fisher's exact tests. All data were analysed using Minitab for Windows, version 11.11 (Minitab Inc., Philadelphia, USA). 
Table 1 Characteristics of patients

\begin{tabular}{|c|c|c|c|}
\hline & Group F & Group P & Defaulters \\
\hline Total no. & 19 & 18 & 15 \\
\hline No. of males & 13 & 14 & 13 \\
\hline Age (mth), mean (SD) & $9.8(2.6)$ & $8.9(2.9)$ & 9.1 \\
\hline \multicolumn{4}{|l|}{ Presenting symptom } \\
\hline Persistent wheeze & 9 & 10 & 8 \\
\hline Recurrent wheeze & 2 & 1 & 4 \\
\hline Persistent cough & 8 & 7 & 3 \\
\hline Personal history of eczema & 7 & 9 & 6 \\
\hline IgE (IU), median (range) & $5 \quad(1-449)$ & $12.5(1-111)$ & \\
\hline \multicolumn{4}{|l|}{ Family history of: } \\
\hline Asthma & 18 & 15 & 9 \\
\hline Eczema & 13 & 15 & 9 \\
\hline Hay fever & 16 & 11 & 13 \\
\hline Ongoing parental smoking & 7 & 7 & 7 \\
\hline Maternal smoking in pregnancy & 4 & 4 & 5 \\
\hline Pets & 9 & 11 & 6 \\
\hline
\end{tabular}

Table 2 Change in diary scores between run in and period 6

\begin{tabular}{|c|c|c|c|}
\hline & \multicolumn{2}{|c|}{ Mean change (SEM) } & \multirow{2}{*}{$\begin{array}{l}\text { Mean difference between } \\
\text { groups } F \text { and } P(95 \% C I)\end{array}$} \\
\hline & Group F & Group P & \\
\hline Day wheeze & $-0.24(0.10)^{\star}$ & $0.03(0.10)$ & $-0.27(-0.03$ to 0.58$)$ \\
\hline Day cough & $-0.30(0.15)$ & $0.18(0.15)$ & $-0.48(0.01$ to 0.89$) \dagger$ \\
\hline Day score & $-0.54(0.23)^{\star}$ & $0.19(0.22)$ & $-0.73(0.08$ to 1.38$) \dagger$ \\
\hline Night wheeze & $-0.16(0.08)$ & $-0.10(0.07)$ & $-0.06(-0.16$ to 0.27$)$ \\
\hline Night cough & $-0.27(0.13)$ & $0.08(0.13)$ & $-0.35(-0.03$ to 0.72$)$ \\
\hline Night score & $-0.43(0.17)^{\star}$ & $-0.02(0.18)$ & $-0.41(-0.09$ to 0.90$)$ \\
\hline Mean daily symptom score & $-0.95(0.38)^{\star}$ & $0.17(0.37)$ & $-1.12(0.05$ to 2.18$) \dagger$ \\
\hline Symptom free days & $3.84(1.26)^{\star}$ & $0.17(1.14)$ & $3.0 \ddagger(0.002$ to 8.0$) \dagger$ \\
\hline Exacerbation days & $-0.11(0.39)$ & $-0.11(0.25)$ & $0.0(-0.96$ to 0.94$)$ \\
\hline Doses of salbutamol & $-0.22(0.13)$ & $0.12(0.24)$ & $-0.34(-0.23$ to 0.91$)$ \\
\hline
\end{tabular}

${ }^{\star} \mathrm{p}<0.05$, change in score between run in and period 6 within group.

$t \mathrm{p}<0.05$, comparison of mean changes between groups.

$\ddagger$ Mann-Whitney test (median not mean).

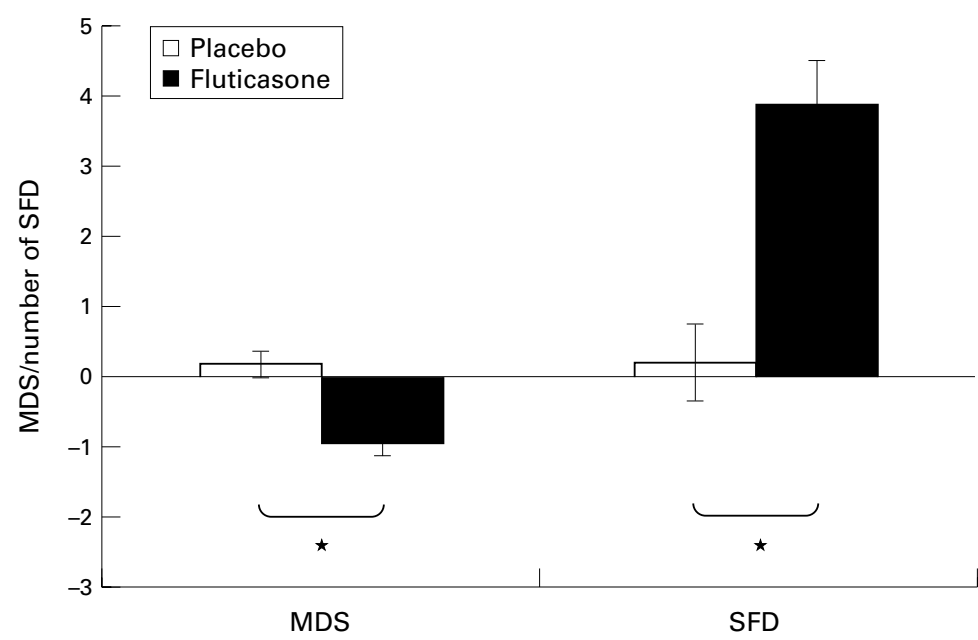

Figure 1 Changes in scores between run in and weeks $11-12 .{ }^{*} p<0.05$.

\section{Results}

A total of 52 infants were recruited; 37 had complete diaries for the total 14 weeks and were included in the analysis, 15 failed to complete the study.

Table 1 details the characteristics of the 37 infants who completed the whole study; infants were randomised to receive either fluticasone (group $\mathrm{F}, \mathrm{n}=19$ ) or placebo (group $\mathrm{P}, \mathrm{n}=18$ ). There were no significant differences between the two treatment groups, or in comparison with those who failed to complete the trial (defaulters).

Seven of the 15 infants who defaulted were in the fluticasone group. Ten infants withdrew during the first eight weeks with no diary data submitted and five withdrew during the final six weeks (one diary submitted). Of the 15 defaulters, three (two from group F) never started the trial and eight (three from group F) stopped treatment as the parent no longer wished to continue, or failed to attend on multiple occasions (three during the final six weeks). One patient (group P) was commenced on inhaled corticosteroid by their GP, one (group F) stopped treatment during a nonassociated illness, and one (group P) because of relocation. One (group F) completed the whole study but was subsequently found to have no data recorded for the run in period.

Only four infants in total had IgE concentrations raised above the upper limit of normal ( $<29$ IU) and there were no statistical differences between groups with group medians of 5.0 IU for group $\mathrm{F}$ and 12.5 IU for group $\mathrm{P}$ (Mann-Whitney test, $\mathrm{p}=0.1$ ).

Six recruits had had a previous admission to hospital with a respiratory disorder. Of these, two had negative viral cultures and immunofluorescence tests at the time of admission, two were not tested (admission not during the respiratory syncytial virus (RSV) season), and two had RSV isolated at some time (both in group P). One of these had had recurrent wheeze prior to the RSV infection, the other being recruited nine months after an RSV infection in the first weeks of life.

Table 2 shows the mean change in scores between the run in period and period 6 for both groups and the mean difference in change with $95 \%$ confidence intervals between the two groups. Figure 1 presents the data for mean change in MDS and SFD graphically. The bars represent the standard error of the mean change (SEM). The difference in change of MDS, and the difference in change of SFD, between group $\mathrm{F}$ and $\mathrm{P}$ are both statistically significant.

Figures 2 and 3 show the changes in MDS and SFD throughout the study period in two week periods. A systematic improvement can be seen in group F for both MDS (fall) and SFD (rise) throughout the study. There is no corresponding improvement in group P. Even by the end of the study it was unclear whether a plateau had been reached in group $\mathrm{F}$.

To exclude the possibility that the significant change in scores reflected only part of the data recorded, we performed a linear regression on the seven data points for MDS from each infant (Minitab). The slope of each resulting line was then taken and the mean slope for each group compared. There was again a significant difference between groups with the mean slope coefficient for the fluticasone group -0.107 (SEM 0.064) compared to +0.079 (SEM 0.061 ) in the placebo group with a mean difference of 0.186 (95\% CI: 0.007 to 0.366 ).

Twenty seven of the infants underwent pulmonary function tests ( 14 in group $F$ ). The mean $\mathrm{V}_{\text {maxFRC }}^{\prime}\left(1 . \mathrm{s}^{-1}\right.$ ) was 143.1 (SD 67.2) in group $\mathrm{F}$ and 156.6 (97.4) in group $\mathrm{P}$. The mean $\mathrm{R}_{\mathrm{rs}}\left(\mathrm{kPa} . \mathrm{l}^{-1} \mathrm{~s}\right.$ ) for group $\mathrm{F}$ was 4.06 (SD 1.04) and for group $P$ was 4.41 (1.41). There 


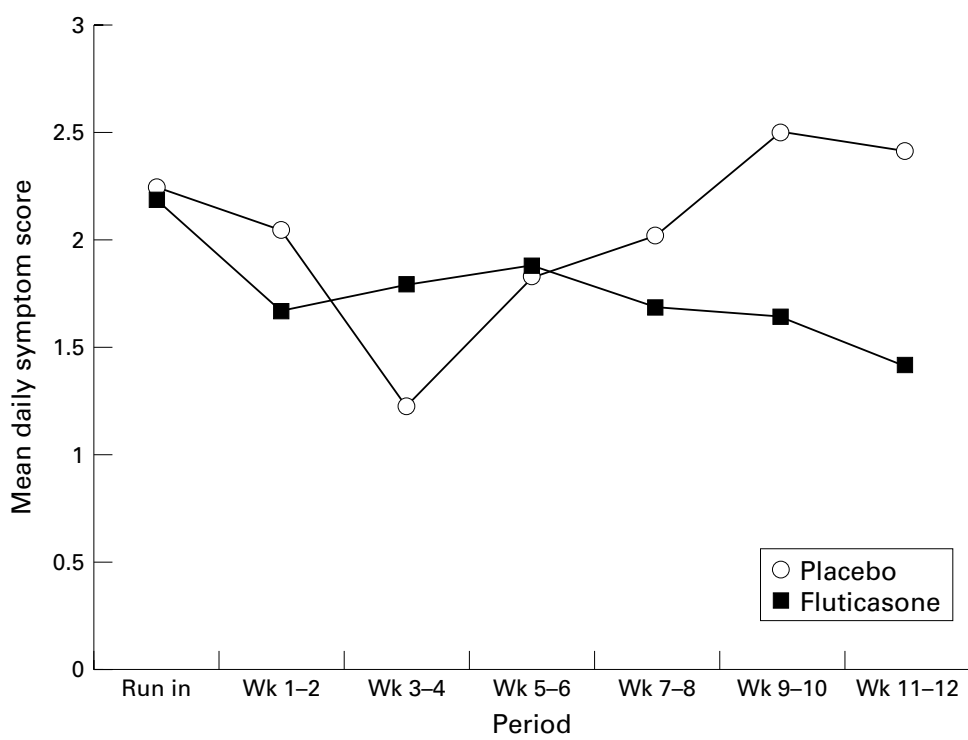

Figure 2 Changes in mean daily symptom score.

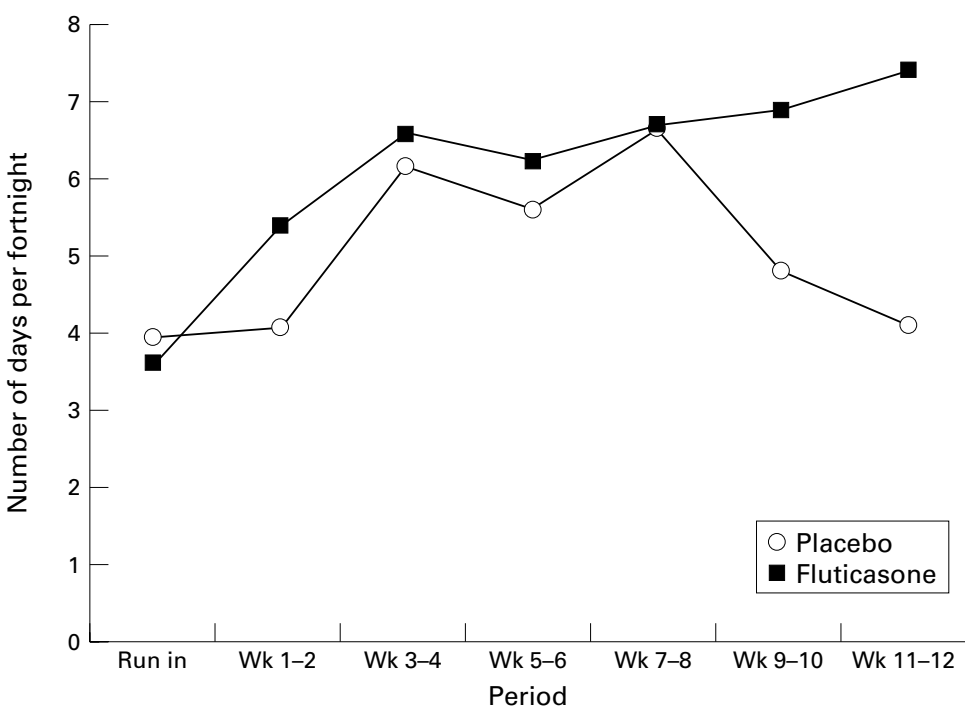

Figure 3 Change in symptom free days.

Table 3 Growth data

\begin{tabular}{lccc}
\hline & Group F & Group P & $\begin{array}{l}\text { Mean difference between } \\
\text { groups F and } P \text { (95\% CI) }\end{array}$ \\
\hline Weight-recruitment (kg, SD) & $9.62(0.87)$ & $9.17(1.01)$ & $0.45(-1.08$ to 0.18$)$ \\
Length-recruitment (cm, SD) & $72.8(3.86)$ & $71.3(4.40)$ & $1.5(-4.3$ to 1.21$)$ \\
Weight change (SEM) & $0.77(0.10)$ & $1.02(0.11)$ & $-0.25(-0.05$ to 0.56$)$ \\
Length change (SEM) & $4.78(0.41)$ & $5.19(0.45)$ & $-0.41(-0.82$ to 1.66$)$ \\
\hline
\end{tabular}

were no significant differences between the two groups.

Table 3 shows the weight and length at recruitment and their change during the study. All infants gained in weight and length: there was a trend to slower gain in group $\mathrm{F}$ but this did not reach significance.

\section{Discussion}

This study aimed to assess the response to inhaled steroids in a group of infants at high risk of developing asthmatic symptoms in childhood. All infants had a clear history of troublesome, ongoing symptoms and a personal or family history of atopy.
We were able to show a significant fall in mean daily symptom score over the study period associated with a rise in the number of symptom free days in the fluticasone group. Previous studies have shown conflicting results. Five studies have shown an improvement in symptoms, ${ }^{912-14} 22$ but two others ${ }^{10}{ }^{11}$ showed no significant effect. Of the positive studies, four recruited infants over a wider age range with some patients up to 3 years of age. Only the study of Noble and colleagues ${ }^{9}$ recruited patients exclusively below 18 months of age, but this study suffers from a more heterogeneous group of recruits and a 50\% noncompletion rate with, subsequently, small numbers. None of these studies have solely recruited patients with a tendency to atopy, which may predispose them to ongoing symptoms in later childhood.

The results from crossover studies ${ }^{9}{ }^{10}$ should also be considered with caution because of uncertainty of wash out of the medication between phases for the subjects treated with active medication first. Inhaled corticosteroids have been shown to have a protective effect for at least 12 weeks after cessation. ${ }^{12}$ This may explain the negative results from Van Bever and colleagues, ${ }^{10}$ although their treatment period was also short (six weeks) and they used nebulised medication which may be less efficiently deposited in the lungs. We chose a parallel design that allowed a longer treatment period without making the total length of the study prohibitive. The improvement we observed in mean daily symptom score in the treatment group did not reach statistical significance until after eight weeks of treatment.

Two studies have attempted to measure a more objective effect using pulmonary function tests. Stick and colleagues ${ }^{11}$ could not measure a response to beclomethasone either by pulmonary function testing or symptom score, their only positive finding being a potential beneficial effect on bronchial responsiveness. Their equivalent dose of steroid was lower than in our study and the duration of their study was shorter (nine weeks) which, coupled with smaller numbers, may have hidden a response. Kraemer and colleagues ${ }^{22}$ measured thoracic gas volume and airway conductance by plethysmography before and after a six week course of beclomethasone. They showed an improvement in the infants randomised to beclomethasone but this was not repeated in a second group of infants on open steroid treatment.

Studies recruiting infants with, or recovering from acute bronchiolitis, have shown an almost uniformly negative response. ${ }^{18-20}$ In our study only six patients had required hospital admission prior to recruitment and only two of these had evidence of RSV bronchiolitis. One of these two infants had wheezed consistently before this diagnosis and the other had had bronchiolitis at 3 weeks of age, nine months prior to recruitment. We did not specifically test for nor exclude patients with previous RSV infection, as most infants are likely to encounter the virus at some stage in the first year of life. 
The most frequently used outcome criterion recorded is the mean daily ${ }^{92}$ (weekly ${ }^{11}$ ) symptom score. The number of symptom free days may be a more robust measure as it is potentially less subjective. It is likely to be easier to discriminate between symptom present versus symptom absent than symptom mild versus symptom moderate. This outcome has not been reported in many of the previous studies in this age group. ${ }^{91012} 1422$ In our study, although there was an initial increase in the number of symptom free days in both groups, this was not maintained in the placebo group for the length of the study, whereas the number of SFD increased systematically in the active treatment group.

We did not show any significant effect of fluticasone on growth. However, there was a trend towards a slowing of weight gain and linear growth in group $\mathrm{F}$, and it is possible that this did not reach significance because of the relatively small size of the study and the study duration. This needs to be re-examined in a longer term, larger study.

We did not attempt to measure the adherence to treatment in this study. The total study length was five months and families had already participated in the two month bronchodilator study. ${ }^{6}$ To have progressed this far, we considered the families were generally strongly motivated. This is a potential criticism of the study, although the effect of poor adherence would, if anything, weaken the difference between groups.

We were unable to show any relation between baseline pulmonary function and response to treatment. As a result of study design and the nature of the tests, the sample size was too small to draw any firm conclusions from this.

In conclusion, we have shown an improvement in symptom score and an increase in symptom free days in infants with troublesome wheeze and an atopic tendency, following treatment with inhaled fluticasone. In the light of repeated studies showing the poor efficacy of inhaled $\beta_{2}$ agonists in infants and the potential benefits of early treatment, the use of inhaled corticosteroids should be seriously considered in infants considered to be at risk of persisting symptoms. Clearly this potential benefit needs to be weighed against the possibility of adverse effects, which requires further investigation, and the knowledge that many wheezy infants (even with an atopic background) will improve spontaneously with age. ${ }^{23}$

We would like to thank Glaxo Wellcome for the provision of inhalers and spacers for this study, Professor John Price (King's College, University of London) for his advice on study design, College, University of London) for his advice on study design,
and Dr D Robinson (University of Sussex) for his advice on statistical analysis. Dr R Chavasse, Dr T Hilliard, Sr Y Bastian-Lee, and Sr H Richter were funded by the Rockinghorse Bastian-
Appeal.

1 Silverman $\mathrm{M}$, Wilson NM. Wheezing disorders in infancy. In: Silverman M, ed. Childhood asthma and other wheezing disorders. London: Chapman \& Hall; 1995:375-400.

2 Martinez FD, Wright AL, Taussig LM, et al. Asthma and wheezing in the first six years of life. $N$ Engl $f \mathrm{Med}$ 1995;332:133-8.

3 Pedersen S. Early use of inhaled steroids in children with asthma. Clin Exp Allergy 1997;27:995-9.

4 Sly PD, Lanteri CJ, Raven JM. Do wheezy infants recovering from bronchiolitis respond to inhaled salbutamol. Pediatr Pulmonol 1991;10:36-9.
5 Prahl P, Tonnes Petersen N, Hornsleth A. Beta2-agonists for the treatment of wheezy bronchitis? Ann Allergy 1986;57: the treatm.

6 Chavasse RJ, Bastian-Lee Y, Richter H, et al. Inhaled salbutamol for wheezy infants: a randomised controlled trial. Arch Dis Child 2000;82:370-5.

7 Balfour-Lynn I. Why do viruses make infants wheeze? Arch Dis Child 1996;74:251-9.

8 Warner JO. The downside of early intervention with inhaled corticosteroids. Clin Exp Allergy 1997;27:1001-4.

9 Noble V, Ruggins NR, Everard ML, Milner AD. Inhaled budesonide for chronic wheezing under 18 months of age. Arch Dis Child 1992;67:285-8.

10 Van Bever HP, Schuddinck L, Wojciechowski M, Stevens WJ. Aerosolised budesonide in asthmatic infants: a double blind study. Pediatr Pulmonol 1990;9:177-80.

11 Stick SM, Burton PR, Clough JB, et al. The effects of inhaled beclomethasone dipropionate on lung function and histamine responsiveness in recurrently wheezy infants. Arch Dis Child 1995;73:327-32.

12 de Blic J, Delacourt C, Le Bourgeois M, et al. Efficacy of nebulised budesonide in treatment of severe infantile asthma: a double-blind study. $\mathcal{F}$ Allergy Clin Immunol 1996;
98.

13 de Benedictis FM, Martinati LC, Solinas LF, et al. Nebulised flunisolide in infants and young children with asthma. Pediatr Pulmonol 1996;21:310-15.

14 Bisgaard H, Munck SL, Nielsen JP, et al. Inhaled budesonide for treatment of recurrent wheezing in early childhood. Lancet 1990;336:649-51.

15 Bisgaard H, Gillies J, Groenwald M, Maden C. The effect of inhaled fluticasone propionate in the treatment of young asthmatics children. A dose comparison study. Am $\mathcal{F}$ Respir Crit Care Med 1999;160:126-31.

16 Roosevelt G, Sheehan K. Dexamethasone in bronchiolitis: a randomised controlled trial. Lancet 1996;348:292-5.

17 De Boeck K, Van der Aa N, Van Lierde S, et al. Respiratory syncytial virus bronchiolitis: a double-blind dexamethasyncytial virus bronchiolitis: a double-blind
sone efficacy study. $\mathcal{F}$ Pediatr 1997;131:919-21.

18 Richter H, Seddon P. Early nebulised budesonide in the treatment of bronchiolitis and the prevention of postbrontreatment of bronchiolitis and the prevention of
chiolitic wheezing. F Pediatr 1998;132:849-53.

19 Fox GM, Everard ML, Marsh MJ, Milner AD. Randomised controlled trial of budesonide for the prevention of post-bronchiolitis wheezing. Arch Dis Child 1999;80:343-7.

20 Cade A, Brownlee KG, Conway SP, et al. Randomised placebo controlled trial of nebulised corticosteroids in acute respiratory syncitial viral bronchiolitis. Arch Dis Child 2000;82:126-30.

21 Tootill JPR, Robinson WD, Eagle DJ. An asymptotically random tauseworthe sequence. Fournal of the Association for Computing Machinery 1973;20:469-81.

22 Kraemer R, Graf Bigler U, Casaulta Aebischer C, et al. Clinical and physiological improvement after inhalation of low-dose beclomethasone dipropionate and salbutamol in wheezy infants. Respiration 1997;64:342-9.

23 Sporik R, Holgate ST, Cogswell JJ. Natural history of asthma in childhood - a birth cohort study. Arch Dis Child 1991;66:1050-3.

\section{Commentary}

A few months ago, in a commentary on a paper by Rusconi and colleagues, ${ }^{1}$ we supported a previous call ${ }^{2}$ for a change of name for infection related wheeze in the early years of life.

At one time, it was the practice in British paediatrics to divide wheezing children into a variety of diagnostic categories. One such category was asthma, which was regarded as an allergic disorder with significant psychological overlay, and which apparently accounted for only a small proportion of childhood wheezing illness. ${ }^{3}$ The others, who wheezed mainly in the presence of upper respiratory tract infection, were allocated to a variety of categories of bronchitis, such as wheezy bronchitis, spastic bronchitis, and asthmatic bronchitis, on the assumption that the viral infection involved the lower as well as the upper airways.

Medical thinking changed with the publication of an epidemiological study by Williams and $\mathrm{McNicol},{ }^{4}$ who reported that they were unable to distinguish wheezy bronchitis from asthma. Thereafter it became the practice to lump rather than to split; all children with recurrent wheeze were considered to be asthmatic until proven otherwise. For most older children with wheeze, such lumping was advantageous, as it led to a reduction in the 
number of courses of antibiotic for nonexistent or viral "chest infections", and to an increase in the number of patients offered the new antiasthma drugs that were developed in the early 1970s.

However, the situation is different for younger children. The diagnosis of bronchitis certainly carries with it the risk of inappropriate antibiotic use, but the diagnosis of asthma is equally problematical. Cromoglycate has little $^{5-7}$ or $\mathrm{no}^{8-10}$ effect in this age group, and inhaled corticosteroids have given variable results, ${ }^{11-14}$ reflecting a variety of problems in assessing drug therapy in this age group.

The first of these is the fact that wheeze in the very young is not a single condition, but has several aetiologies, the foremost of which is virus associated wheeze. This condition differs from asthma in being triggered only by upper respiratory tract infection, and does not progress to asthma in later childhood..$^{15}{ }^{16}$ The liability to continuing wheeze is strongly predicted by a family history of asthma and a personal history of allergy, but not by the results of skin tests or IgE concentrations. ${ }^{17}$ Trials of asthma drugs usually select patients on the basis of the severity or frequency of the wheeze rather than its triggers, and do not usually stipulate the allergic status of the patients or their families.

A second problem is the difficulty in achieving adequate drug deposition in the airways, ${ }^{18}$ although the more recent inhalation devices appear to be more satisfactory in this respect. $^{12} 19$

Thirdly, the nature of the bronchial obstruction may be different in infants, reflecting underlying anatomical abnormality ${ }^{20}$ or differences in the inflammatory process. ${ }^{21}$

There is therefore a clear need in therapeutic trials to define the type of wheeze that is being treated. This is not only more likely to produce an unequivocal result, compared to some of the marginal results obtained in the studies cited above, but also facilitates the application of the results in clinical practice. In this paper, Chavasse and his colleagues report just such a trial.

They chose to study infants aged between 3 and 6 months of age with persistent wheeze, persistent cough, or recurrent wheeze, and who were predisposed to the longer term persistence of their symptoms by virtue of a personal or family history of allergy. In other words, they split rather than lumped infantile wheeze, and selected for study a group of infants who would formerly have been diagnosed as having asthma rather than bronchitis. Although the inclusion of coughing children might be debated, the proof of this particular pudding is in the results, and the patients in the active arm of the trial fared significantly better than did those on placebo.

This then is a study that might change medical practice. From now on, the paediatrician faced with a child with recurrent or persistent lower respiratory tract symptoms can tell the parents that, in the group most likely to go on to asthma, there is a drug that can make a difference. If he is completely honest, he will also point out that the trial was a short one, and involved a relatively small number of patients, so it is too soon to comment on long term benefits and safety.

The paediatrician will also be able to state that, in the group not predisposed to persistent wheeze by virtue of a family or personal history of atopy, the prognosis is generally benign, treatment is both unnecessary and ineffective, and the wheeze will most likely settle by the time the child is of school age.

It would greatly facilitate the task of this paediatrician if he or she had suitable names to describe these two groups of patients. Asthma is the obvious choice for the allergic group, but virus associated wheeze seems a cumbersome title for the others, and unlikely to find much favour for everyday use.

Come back wheezy bronchitis, all is forgiven - and we promise not to mistreat you with antibiotics.

GEORGE RUSSELL

Department of Child Health, University of Aberdeen AB25 2ZD(gxr@iahs.abdn.ac.uk).

1 Rusconi F, Patria MF, Cislaghi GV et al. Total serum IgE and outcome in infants with recurrent wheezing. Arch Dis Child 2000;85:23-5.

2 Silverman M, Wilson N. Asthma-time for a change of name? Arch Dis Child 1997;77:62-4

3 Logan WPD, Cushion AA. Morbidity statistics from general practice. Studies on Medical and Population Subjects, Vol 14. General Register Office. London: HMSO, 1958.

4 Williams H, McNicol KN. Prevalence, natural history, and relationship of wheezy bronchitis and asthma in children. An epidemiological study. BMF 1969;4:321-5.

5 Glass J, Archer LN, Adams W, Simpson H. Nebulised cromoglycate, theophylline, and placebo in preschool asthmoglycate, theophylline, and placebo in prescho
matic children. Arch Dis Child 1981;56:648-51.

6 Geller-Bernstein C, Levin S. Nebulised sodium cromoglycate in the treatment of wheezy bronchitis in infants and young children. Respiration 1982;43:294-8.

7 Cogswell JJ, Simpkiss MJ. Nebulised sodium cromoglycate in recurrently wheezy preschool children. Arch Dis Child 1985;60:736-8.

8 Bertelsen A, Andersen JB, Busch P, et al. Nebulised sodium cromoglycate in the treatment of wheezy bronchitis. A multicentre double-blind placebo controlled study. Allergy 1986;41:266-70

9 Furfaro S, Spier S, Drblik SP, et al. Efficacy of cromoglycate in persistently wheezing infants. Arch Dis Child 1994;71: $331-4$.

10 Tasche MJ, van der Wouden JC, Uijen JH, et al. Randomised placebo-controlled trial of inhaled sodium cromoglycate in placebo-controlled trial of inhaled sodium cromoglycate in 350:1060-4.

11 Van Bever HP, Schuddinck L, Wojciechowski M, Stevens WJ. Aerosolized budesonide in asthmatic infants: a double blind study. Pediatr Pulmonol 1990;9:177-80.

12 Wilson NM, Silverman M. Treatment of acute, episodic asthma in preschool children using intermittent high dose inhaled steroids at home. Arch Dis Child 1990;65:407-10.

13 Wilson N, Sloper K, Silverman M. Effect of continuous treatment with topical corticosteroid on episodic viral wheeze in preschool children. Arch Dis Child 1995;72:31720 .

14 de Blic J, Delacourt C, Le Bourgeois M, et al. Efficacy of nebulized budesonide in treatment of severe infantile asthma: a double-blind study. $\mathcal{F}$ Allergy Clin Immunol 1996; 98:14-20.

15 Park ES, Golding J, Carswell F, Stewart-Brown S. Preschool wheezing and prognosis at 10. Arch Dis Child 1986;61: 642-6.

16 Wilson NM. The significance of early wheezing. Clin Exp Allergy 1994;24:522-9.

17 Wilson NM, Dore CJ, Silverman M. Factors relating to the severity of symptoms at 5 yrs in children with severe wheeze in the first 2 yrs of life. Eur Respir $\mathcal{F}$ 1997;10:34653.

18 Salmon B, Wilson NM, Silverman M. How much aerosol reaches the lungs of wheezy infants and toddlers? Arch Dis Child 1990;65:401-3.

19 Kraemer R, Graf BU, Casaulta AC, et al. Clinical and physiological improvement after inhalation of low-dose beclomethasone dipropionate and salbutamol in wheezy infants. Respiration 1997;64:342-9.

20 Martinez FD, Wright AL, Taussig LM, et al. Asthma and wheezing in the first six years of life. $N$ Engl $7 \mathrm{Med}$ 1995;332:133-8.

21 Balfour-Lynn IM. Why do viruses make infants wheeze? Arch Dis Child 1996;74:251-9. 